\title{
Focused Assessment with Sonography in Trauma (FAST) Scans Are Not Sufficiently Sensitive to Rule out Significant Injury in Pediatric Trauma Patients
}

\author{
Clare Skerritt, Saira Haque, Erica Makin \\ Department of Pediatric Surgery, The Royal London Hospital, London, UK \\ Email: erica.makin@ntlworld.com
}

Received 9 July 2014; revised 5 August 2014; accepted 2 September 2014

Copyright (C) 2014 by authors and Scientific Research Publishing Inc.

This work is licensed under the Creative Commons Attribution International License (CC BY). http://creativecommons.org/licenses/by/4.0/

\section{(c) (i) Open Access}

\begin{abstract}
Aim: To assess the sensitivity and specificity of FAST scans in pediatric trauma in a dedicated pediatric trauma centre. Method: A 3-year (2008-2011) analysis of prospectively collected data looking at the results of FAST scans compared to Computed Tomography (CT) or laparotomy findings. Results: There were 482 pediatric trauma calls of which 166 patients had suspected intra-abdominal injury. 163 patients underwent CT scans of which $89(55 \%)$ had FAST scans prior to CT. 3 patients had FAST scans without CT; 1 patient went straight to theatre (positive FAST) and 2 patients died in the department before any further imaging. The sensitivity of FAST scans to detect abdominal injury is $\mathbf{2 3} \%$ and the specificity is $\mathbf{9 7 \%}$. The injuries missed on FAST scan were: liver lacerations $(n=3)$, splenic lacerations $(n=5), 1$ combined liver and kidney injury and 1 combined splenic injury and small bowel perforation. Conclusions: FAST scans in trauma have a low sensitivity in pediatric patients with the possibility of missing significant intra-abdominal injury. They do not obviate the need for CT scan when clinical suspicion is high.
\end{abstract}

\section{Keywords}

Blunt Trauma, Ultrasound, FAST

\section{Introduction}

The clinical use of Focused Assessment with Sonography in Trauma (FAST) scans has gained increasing acceptance in the management of adult trauma patients and is used in up to $96 \%$ of adult trauma centers in the 
United States. However, its adoption into pediatric trauma centers is considerably less at $15 \%$ [1].

Debate still continues as to their accuracy in assessing pediatric trauma patients. Some centers favor formal ultrasound instead of FAST scans. Retzlaff et al. showed that ultrasound was effective in managing 97\% of pediatric patients who had suffered intra-abdominal injuries as a result of blunt abdominal trauma and that CT only influenced decision making in 1 out of their 35 patients [2].

Our hospital is a level-one trauma center and FAST scans are performed routinely in adults, the results of which are relied upon to guide management. The same emergency department (ED) trauma team also covers pediatric trauma calls and performs FAST scans in pediatric patients. There has been continued debate between ED staff and the pediatric surgeons as to the reliability of these scans to influence management in pediatric patients. During the study period due to concerns about their sensitivity in children, we had a low threshold for CT scanning all haemodynamically stable children with a significant mechanism of injury.

The aim of the study is to determine the sensitivity and specificity of FAST scans in assessing pediatric trauma patients to establish if they can be a reliable alternative to CT scanning and thus reduce radiation exposure [3]-[5] which may lead to an increased lifetime risk of malignancy.

\section{Materials and Methods}

Data were analyzed from a prospectively maintained database of all pediatric trauma patients over a 3-year period from May 2008 to May 2011. FAST scans were performed by either an emergency department physician (minimum of level-1 in ultrasound training accredited by the College of Emergency Medicine) or a Radiologist (Specialist Trainee year 1 and above). FAST scans were used following blunt trauma and the scan was limited to 4 views (left and right upper abdominal quadrants, pelvic and pericardial) looking for the presence of free fluid. It did not assess the integrity of solid intra-abdominal organs. The result was recorded as positive if any free fluid was identified. No attempt was made to quantify the volume of free fluid. There were some shifts when trained FAST practitioners did not staff the department and therefore not all trauma patients received FAST scans.

Patients who were haemodynamically stable and had either a mechanism of injury that could have caused intra-abdominal injury or abdominal tenderness then underwent CT scans with intravenous contrast. The departmental protocol aims to scan haemodynamically stable patients within 10 minutes of arrival and there was minimal delay between the FAST and CT scan. All CT scans demonstrating an intra-abdominal injury have been secondarily reviewed by a Consultant Pediatric Radiologist with respect to grading of solid organ injuries in alignment with the American Association for the Surgery of Trauma (AAST) classification, together with an assessment of the degree of free fluid within the abdominal cavity.

Patients were excluded from the study if no FAST was performed or if no further imaging/CT scans were available for comparison. We did not use clinical follow-up alone as definitive evidence of no intra-abdominal injury. CT scan or findings at laparotomy were considered the gold standard for comparison of FAST scan findings.

Statistical analysis was performed using Graphpad Prism V 5.0 to determine sensitivity, specificity, positive and negative predictive values of FAST scans in detecting intra-abdominal injury following blunt trauma.

\section{Results}

There were 482 pediatric trauma calls secondary to blunt trauma over a three year period. 166 patients had suspected intra-abdominal injuries, of these 163 patients had CT scans. 89 (55\%) received FAST scans prior to the CT. 3 further patients had FAST scans. 1 patient went straight to theatre due to haemodynamic instability (positive FAST) and underwent a splenectomy, 2 patients were pronouced dead on arrival in the emergency department prior to any further imaging.

The median age at time of injury was 10.2 years (range 0.5 - 16.3 yrs). 70 patients were male (76\%) and the median Injury Severity Score (ISS) was 11 (range 0 - 75) of which $46 \%$ had an ISS $>15$ indicating severe trauma. The median time from injury to arrival in the emergency department resuscitation room was 59 minutes (range 7 - 418 minutes).

The commonest mechanism of injury was road traffic accidents $(n=66)$ and reflecting our hospital's inner city setting the majority of patients $(75 \%)$ had been pedestrians hit by vehicles rather than passengers. The second commonest mechanism of injury was falls from height. $(n=22)$ (Table 1$)$. 
Table 1. Mechanism of Injuries.

\begin{tabular}{cccc}
\hline Mechanism of Injury & Number of Patients & Median Age (yrs) [Range] & Median Injury Severity Score [Range] \\
\hline All & 92 & $10.2[0.5-16.3]$ & $11[0-75]$ \\
Road traffic accidents & & & $11[0-50]$ \\
Pedestrian vs. car & 49 & $10.0[0.5-16.3]$ & $10[2-29]$ \\
Passenger & 11 & $11.0[2.8-14.3]$ & $3[1-5]$ \\
Cyclist & 2 & $11.5[7.8-15.2]$ & $8.5[4-15]$ \\
Motorbike & 4 & $14.1[11.3-15.9]$ & $10[0-75]$ \\
Fall from height & 22 & $10.4[1.4-16.3]$ & $27[2-45]$ \\
\end{tabular}

Miscellaneous = hit by metal bar from loader, trapped by electric gates, unknown $=2$.

Seven patients had a positive FAST scan (6 road traffic accidents (RTA) and 1 fall from a height). Of these, 5 had significant injuries (ISS > 15). Two patients were declared dead on arrival in the emergency department without surgery (a 5 yrs old boy who was knocked down by a lorry and an $18 \mathrm{mth}$ old boy who had fallen from a $4^{\text {th }}$ floor). These patients were excluded from the analysis of sensitivity of FAST scans. A 3 yrs old boy who was hit by a car required an emergency splenectomy. 2 patients sustained solid organ injuries, one liver injury (AAST grade 3) and one splenic laceration (AAST grade 2), both were successfully managed conservatively. However there were 2 patients with positive FAST scans in whom CT findings were negative.

There were 10 patients (RTA $n=7$, fall $n=3$ ) in whom FAST scans were reported as negative when in fact significant injuries were then discovered on CT scans. The missed injuries included 3 liver lacerations, 1 combined liver and right kidney laceration (Figure 1), 5 splenic injuries and 1 combined splenic injury and small bowel perforation. All injuries were managed conservatively apart from one patient who required a laparotomy to repair a jejunal perforation (Table 2).

Overall mortality was 3.3\% ( $\mathrm{n}=3)$. Two were declared dead on arrival and have already been described. One further patient died within 24 hours of admission following a massive head injury having been a passenger in an RTA.

For the 90 patients that had a FAST scan followed by either a CT scan or laparotomy the sensitivity to detect intra-abdominal injury was $23 \%$, specificity $97 \%$ with a positive predictive value of $60 \%$ and a negative predictive value of $88 \%$ (Table 3 ).

\section{Discussion}

Our study indicates that FAST scans in children have a sensitivity of $23 \%$ and are not sensitive enough to exclude significant intra-abdominal injury. Preliminary studies in children have suggested that ultrasound scans could reduce the use of CT scans in pediatric trauma patients [6] [7]. These studies involved either a full abdominal ultrasound or included assessment of parenchymal integrity of the solid intra-abdominal organs. Richards et al. [8] reported the largest study of ultrasound in pediatric trauma patients. A comparison was made between ultrasound findings and CT/laparotomy in 744 patients. When ultrasound was used to look for free fluid alone the sensitivity to detect intra-abdominal injury was $56 \%$. This improved marginally to $68 \%$ when solid organ parenchyma was also examined. FAST scans in our hospital are restricted to looking for free fluid only. This enables the scan to be performed quickly and negates the need to have extensive radiology training. It could be argued that dedicated medical sonographers or radiologists would obtain more accurate results. However, Mutagabani et al. reported a similar sensitivity to our study of 30\% when all the FAST scans in their study were performed by pediatric radiologists [9].

An explanation for the low sensitivity of FAST in children is that not all intra-abdominal injuries in children are associated with free intra-peritoneal fluid. Taylor and Sivit found that $37 \%$ of intra-abdominal injuries detected by CT were not associated with free fluid [10]. Our study supports this finding since 5 out of the 10 intra-abdominal injuries missed on FAST scan had no or trace free fluid detected on CT scan. There is no litera- 


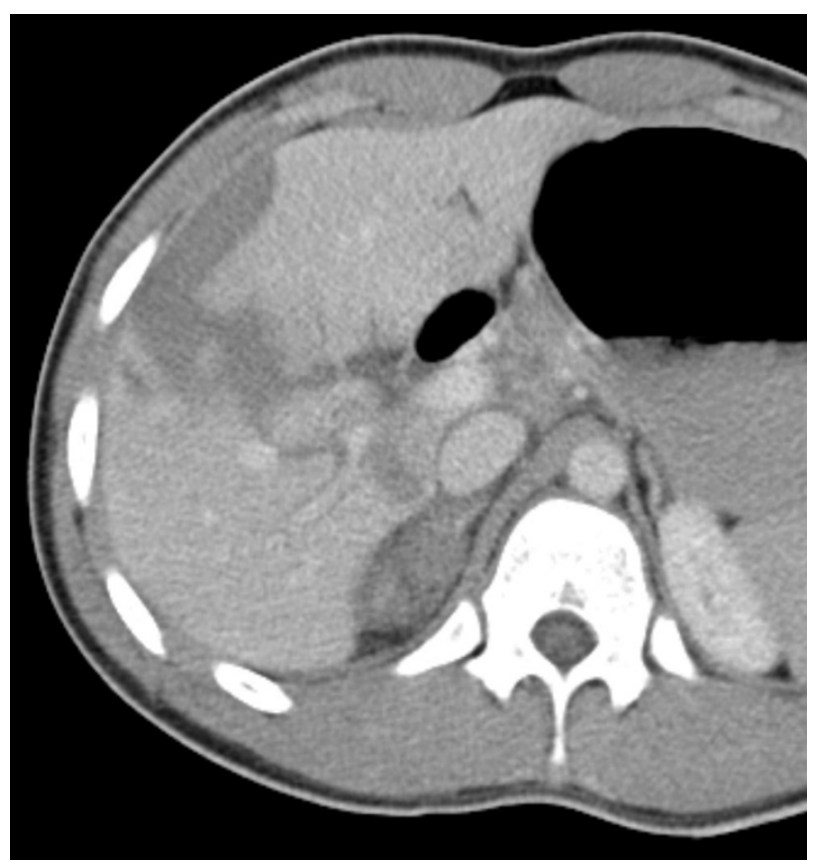

Figure 1. Grade IV liver laceration missed on FAST scan: 9 $\mathrm{cm}$ liver laceration affecting segment $\mathrm{V}$ and VIII, traversing the portal vein.

Table 2. Demographics and injuries sustained when FAST was negative.

\begin{tabular}{|c|c|c|c|c|c|c|c|c|}
\hline $\begin{array}{l}\text { Patient } \\
\text { No }\end{array}$ & Sex & $\begin{array}{l}\text { Age } \\
\text { (yrs) }\end{array}$ & $\begin{array}{l}\text { Mechanism } \\
\text { Injury }\end{array}$ & $\begin{array}{c}\text { Injury Severity } \\
\text { Score }\end{array}$ & Injury & $\begin{array}{l}\text { AAST } \\
\text { Grade }\end{array}$ & $\begin{array}{l}\text { Free Fluid } \\
\text { on CT }\end{array}$ & Treatment \\
\hline 1 & M & 12.4 & RTA & 34 & Liver trauma & 3 & Small & Conservative \\
\hline \multirow[t]{2}{*}{2} & M & 13.9 & Fall & 10 & Liver trauma & 4 & Trace & Conservative \\
\hline & & & & & R Renal trauma & 3 & & \\
\hline 3 & $\mathrm{~F}$ & 15 & RTA & 43 & Liver trauma & 3 & Trace & Conservative \\
\hline 4 & $\mathrm{M}$ & 11.8 & RTA & 45 & Liver trauma & 2 & Trace & Conservative \\
\hline 5 & $\mathrm{M}$ & 9.8 & RTA & 41 & Splenic trauma & 2 & Trace & Conservative \\
\hline 6 & M & 13 & Fall & 21 & Splenic trauma & 3 & Nil & Conservative \\
\hline 7 & $\mathrm{M}$ & 6 & Fall & 4 & Splenic trauma & 4 & Moderate & Conservative \\
\hline 8 & M & 7.6 & RTA & 27 & Splenic trauma & 2 & Small & Conservative \\
\hline 9 & M & 6.8 & RTA & 21 & Splenic trauma & 2 & Small & Conservative \\
\hline 10 & $\mathrm{~F}$ & 4.3 & RTA & 9 & $\begin{array}{c}\text { Splenic trauma } \\
\text { Jejunal perforation }\end{array}$ & 1 & Small & $\begin{array}{c}\text { Laparotomy, } \\
\text { oversewing jejunum }\end{array}$ \\
\hline
\end{tabular}

Abbreviations: $\mathrm{M}=$ male, $\mathrm{F}=$ female, RTA = Road Traffic Accident, AAST = American Association Surgery of Trauma. Definitions free fluid on CT: Trace $=$ Fluid seen on one $5 \mathrm{~mm}$ CT section, Small $=$ Fluid seen on $2-3$ consecutive 5 mm CT sections, Moderate $=$ Fluid seen on 4 - 5 consecutive $5 \mathrm{~mm}$ CT sections, Marked = Fluid seen on $>6$ consecutive $5 \mathrm{~mm}$ sections.

Table 3. Sensitivity and Specificity of FAST scans in pediatric trauma.

\begin{tabular}{lcc}
\hline & CT Positive/Laparotomy & CT Negative \\
\hline FAST positive & 3 & 2 \\
FAST negative & 10 & 75 \\
\hline
\end{tabular}

Sensitivity $=23 \%$ (95\% CI 5\% to 54\%), Specificity = 97\% (95\% CI 90\% to 99\%). PPV = 60\% (95\% CI 15\% to 93\%), NPV = 88\% (95\% CI 79\% to $94 \%)$. 
ture available to suggest how much free fluid needs to be present within the peritoneal cavity of children before it is detectable with ultrasound. A blinded study in adults where fluid for diagnostic peritoneal lavage was infused into patients whilst they were continually scanned with ultrasound over Morison's pouch found that the average volume infused was $400 \mathrm{mls}$ before it was detected [11]. This study is unlikely to be repeated in children however it is possible that injuries are missed due to lower volumes of fluid in the peritoneal cavity in children.There is evidence that FAST scans in children become more accurate in hypotensive patients who have suffered large bleeds [12].

We chose to only look at those patients who had FAST scans followed by CT scan or laparotomy. Those studies [2] [6] [13] [14] supporting the use of FAST scans tend to use clinical follow-up as evidence of no intra-abdominal injury which may well account for their apparent better sensitivity. In adults observation may well be an adequate control, however particularly in young children symptoms and signs may not always manifest until too late. Some authors argue that missed injuries may not be clinically significant and knowledge of the injury does not necessarily influence management. However, in our series two grade IV liver and splenic injuries were missed (Figure 1). These patients were successfully managed conservatively, but knowledge of the extent of solid organ injuries and reassurance of no active bleeding (absent contrast blush on CT) [15] is necessary to support the decision to manage these patients conservatively, preferably on a high dependency unit where any clinical deterioration could be immediately detected. In addition quantification of the extent of injury at the time of trauma provides guidance for planning follow-up imaging to assess for significant sequelae of solid organ injuries such as biliary leaks, urinomas and pseudoaneurysms (both hepatic and splenic) [16].

There have been several papers reporting the sensitivity of FAST scans can be improved when combined with other tests [17] [18]. Suthers et al. [17] reported that the sensitivity of FAST reaches $100 \%$ when considered jointly with the physical examination of the patient performed by the surgeon attending the trauma call. We would argue that in a multiply injured child with a depressed level of consciousness a physical examination will not provide adequate information for decision making and in fact a CT scan becomes vital to ensure no occult injuries are missed.

Within adult practice some authors are beginning to question the role of FAST scans in haemodynamically stable patients [19] [20]. Natarajan et al. [20] looked at over 2000 patients who had undergone FAST scans for blunt trauma and found that in the haemodynamically stable patients there 60 patients with true positive FAST scans and 87 patients with false negative FAST scans. Sensitivity was only $41 \%$ and amongst the false negative FAST scans over a third of patients underwent emergency laparotomy for their injuries. Due to the low sensitivity of FAST scans, a haemodynamically stable patient with a negative scan will still require a CT to avoid missing injuries and a positive FAST scan will also need a confirmatory CT to provide a better understanding of the injuries to guide management. Therefore the authors concluded that FAST scans should be restricted to those patients who are haemodynamically unstable. A recent meta-analysis of FAST scans in children supported this approach [21]. When only the most methodologically sound papers were included in analysis, FAST scan sensitivity was 66\% (56\% - 75\%) and specificity 95\% (93\% - 97\%) for detecting intra-abdominal trauma.

We recognize that our study has limitations. It was performed retrospectively and not all blunt abdominal trauma patients had FAST scans. However it reflects real-life use of FAST scans in the busiest trauma center in the UK. We conducted the study to inform the ongoing debate between emergency department physicians and pediatric surgeons in our hospital regarding how FAST scans can be used to influence management. Scaife et al. [22] conducted a prospective study of the use of FAST scans performed by pediatric trauma surgeons and found very similar results to our study. Interestingly, once the findings were analyzed and reported to staff the use rate decreased from $70 \%$ to $30 \%$ of potential intra-abdominal injury trauma cases. There may be a select group of patients who are haemodynamically unstable at presentation in whom FAST scans may help to determine which body cavity to open first, specifically if there is evidence of cardiac tamponade. However our study does not support the routine use of FAST scans in assessing pediatric trauma patients for the presence of intra-abdominal injury.

\section{Conclusion}

In conclusion, FAST scans are not sensitive enough to rule out significant intra-abdominal injuries in pediatric trauma patients. We would advocate that all haemodynamically stable patients undergo a CT scan when there is a moderate probability of intra-abdominal injury determined by the mechanism of injury. 


\section{Conflicts of Interest}

None.

\section{References}

[1] Scaife, E.R., Fenton, S.J., Hansen, K.W. and Metzger, R.R. (2009) Use of Focused Abdominal Sonography for Trauma at Pediatric and Adult Trauma Centers: A Survey. Journal of Pediatric Surgery, 44, 1746-1749. http://dx.doi.org/10.1016/j.jpedsurg.2009.01.018

[2] Retzlaff, T., Hirsch, W., Till, H. and Rolle, U. (2010) Is Sonography Reliable for the Diagnosis of Pediatric Blunt Abdominal Trauma? Journal of Pediatric Surgery, 45, 912-915. http://dx.doi.org/1016/j.jpedsurg.2010.02.020

[3] Rice, H.E., Frush, D.P., Farmer, D., Waldhausen, J.H. and APSA Education Committee (2007) Review of Radiation Risks from Computed Tomography: Essentials for the Pediatric Surgeon. Journal of Pediatric Surgery, 42, 603-607. http://dx.doi.org/10.1016/j.jpedsurg.2006.12.009

[4] Fenton, S.J., Hansen, K.W., Meyers, R.L., Vargo, D.J., White, K.S., Firth, S.D. and Scaife, E.R. (2004) CT Scan and the Pediatric Trauma Patient-Are We Overdoing It? Journal of Pediatric Surgery, 39, 1877-1881. http://dx.doi.org/j.jpedsurg.2004.08.007

[5] Brenner, D.J. (2002) Estimating Cancer Risks from Pediatric CT: Going from the Qualitative to the Quantitive. Pediatric Radiology, 32, 228-231. http://dx.doi.org/10.1007/s00247-002-0671-1

[6] Akgur, F.M., Aktug, T., Olguner, M., Kovanlikaya, A. and Hakgüder, G. (1997) Prospective Study Investigating Routine Usage of Ultrasonography as the Initial Diagnostic Modality for the Evaluation of Children Sustaining Blunt Abdominal Trauma. Journal of Trauma, 42, 626-628.http://dx.doi.org/10.1097/00005373-199704000-00007

[7] Katz, S., Lazar, L., Rathaus, V. and Erez, I. (1996) Can Ultrasonography Replace Computed Tomography in the Initial Assessment of Children with Blunt Abdominal Trauma? Journal of Pediatric Surgery, 31, 649-651. http://dx.doi.org/10.1016/S0022-3468(96)90666-1

[8] Richards, J.R., Knopf, N.A., Wang, L. and McGahan, J.P. (2002) Blunt Abdominal Trauma in Children: Evaluation with Emergency Ultrasound. Radiology, 222, 749-754.http://dx.doi.org/10.1148/radiol.2223010838

[9] Mutabagani, K.H., Coley, B.D., Zumberge, N., McCarthy, D.W., Besner, G.E., Caniano, D.A. and Cooney D.R. (1999) Preliminary Experience with Focused Abdominal Sonography for Trauma (FAST) in Children: Is It Useful? Journal of Pediatric Surgery, 34, 48-54. http://dx.doi.org/10.1016/S0022-3468(99)90227-0

[10] Taylor, G.A. and Sivit, C.J. (1995) Post Traumatic Fluid: Is It A Reliable Indicator of Intra-Abdominal Injury in Children? Journal of Pediatric Surgery, 30, 1644-1648. http://dx.doi.org/10.1016/0022-3468(95)90442-5

[11] Branney, S.W., Wolfe, R.E., Moore, E.E., Albert, N.P., Heinig, M., Mestek, M. and Eule, J. (1995) Quantitative Sensitivity of Ultrasound in Detecting Free Intraperitoneal Fluid. Journal of Trauma, 39, 375-380. http://dx.doi.org/10.1097/00005373-199508000-00032

[12] Holmes, J.F., Brant, W.E., Bond, W.F., Sokolove, P.E. and Kuppermann, N. (2001) Emergency Department Ultrasonography in the Evaluation of Hypotensive and Normotensive Children with Blunt Abdominal Trauma. Journal of Pediatric Surgery, 36, 968-973. http://dx.doi.org/10.1053/jpsu.2001.24719

[13] Soudack, M., Epelman, M., Maor, R., Hayari, L., Shoshani, G., Heyman-Reiss, A., Michaelson, M. and Gaitini, D. (2004) Experience with Focused Abdominal Sonography for Trauma (FAST) in 313 Pediatric Patients. Journal of Clinical Ultrasound, 32, 53-61.http://dx.doi.org/10.1002/jcu.10232

[14] Patel, J.C. and Tepas III, J.J. (1999) The Efficacy of Focused Abdominal Sonography for Trauma (FAST) as a Screening Tool in the Assessment of Injured Children. Journal of Pediatric Surgery, 34, 44-47. http://dx.doi.org/10.1016/S0022-3468(99)90226-9

[15] Van der Vlies, C.H., Saltzherr, T.P., Wilde, J.C.H., van Delden, O.M., de Haan, R.J. and Goslings, J.C. (2010) The Failure Rate of Nonoperative Management in Children with Splenic or Liver Injury with Contrast Blush on Computed Tomography: A Systematic Review. Journal of Pediatric Surgery, 45, 1044-1049. http://dx.doi.org/10.1016/j.jpedsurg.2010.01.002

[16] Safavi, A., Beaudry, P., Jamieson, D. and Murphy, J.J. (2011) Traumatic Pseudoaneurysms of the Liver and Spleen in Children: Is Routine Screening Warranted? Journal of Pediatric Surgery, 46, 938-941. http://dx.doi.org/10.1016/j.jpedsurg.2011.02.035

[17] Suthers, S.E., Albrecht, R., Foley, D., Mantor, P.C., Puffinbarger, N.K., Jones, S.K. and Tuggle, D.W. (2004) SurgeonDirected Ultrasound for Trauma Is a Predictor of Intra-Abdominal Injury in Children. American Surgeon, 70, 164-167.

[18] Sola, J.E., Cheung, M.C., Yang, R., Koslow, S., Lanuti, E., Seaver, C., Neville, H.L. and Schulman, C.I. (2009) Pediatric FAST and Elevated Liver Transaminases: An Effective Screening Tool in Blunt Abdominal Trauma. Journal of Surgical Research, 157, 103-107. http://dx.doi.org/10.1016/j.jss.2009.03.058 
[19] Miller, M.T., Pasquale, M.D., Bromberg, W.J., Wasser, T.E. and Cox, J. (2003) Not So FAST. Journal of Trauma, 54, 52-60. http://dx.doi.org/10.1097/00005373-200301000-00007

[20] Natarajan, B., Gupta, P.K., Cemaj, S., Sorensen, M., Hatzoudis, G.I. and Forse, R.A. (2010) FAST Scan: Is It Worth Doing in Hemodynamically Stable Blunt Trauma Patients? Surgery, 148, 695-701. http://dx.doi.org/10.1016/j.surg.2010.07.032

[21] Holmes, J.F., Gladman, A. and Chang, C.H. (2007) Performance of Abdominal Ultrasonography in Pediatric Blunt Trauma Patients: A Meta-Analysis. Journal of Pediatric Surgery, 42, 1588-1594. http://dx.doi.org/10.1016/j.jpedsurg.2007.04.023

[22] Scaife, E.R., Rollins, M.D., Barnhart, D.C., Downey, E.C., Black, R.E., Meyers, R.L., Stevens, M.H., Gordon, S., Prince, J.S., Battaglia, D., Fenton, S.J., Plumb, J. and Metzger, R.R. (2013) The Role of Focused Abdominal Sonography for Trauma (FAST) in Pediatric Trauma Evaluation. Journal of Pediatric Surgery, 48, 1377-1383. http://dx.doi.org/10.1016/j.jpedsurg.2013.03.038 
Scientific Research Publishing (SCIRP) is one of the largest Open Access journal publishers. It is currently publishing more than 200 open access, online, peer-reviewed journals covering a wide range of academic disciplines. SCIRP serves the worldwide academic communities and contributes to the progress and application of science with its publication.

Other selected journals from SCIRP are listed as below. Submit your manuscript to us via either submit@scirp.org or Online Submission Portal.
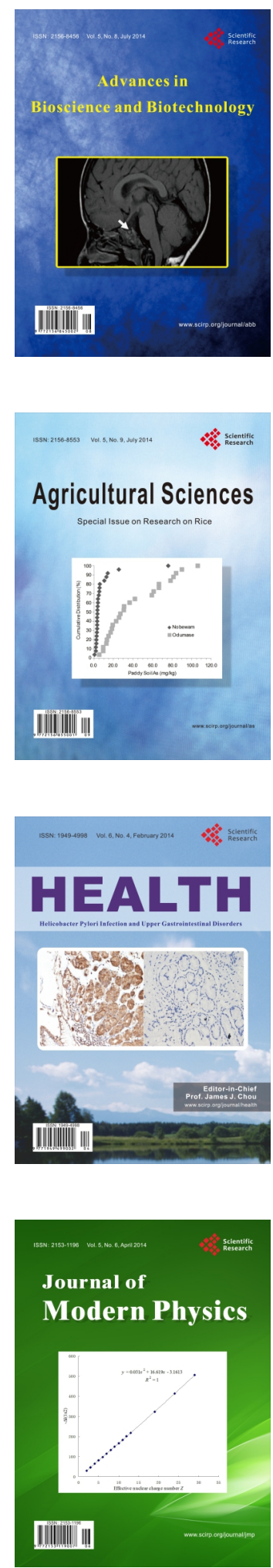
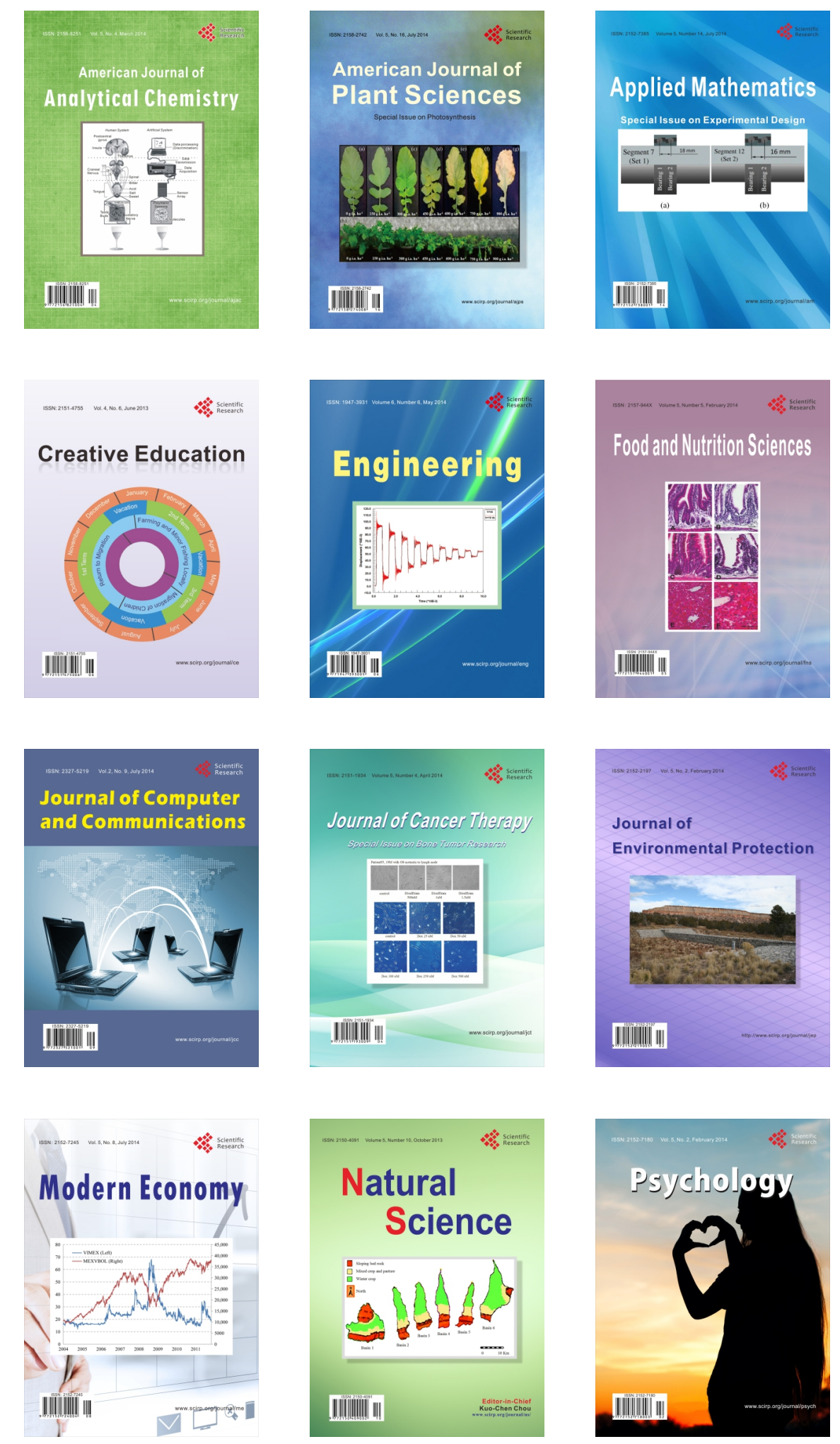